\title{
A Study On Burnout Syndrome and Employee Retention in a Private Hospital During COVID-19 Pandemic
}

\author{
Pheno Mon Joy ${ }^{1 *}$, S. Venkatesh ${ }^{2}$ \\ ${ }^{1}$ M.Phil. Scholar, PRIST School of Business, PRIST Deemed to be University, Thanjavur, India \\ ${ }^{2}$ Associate Professor, PRIST School of Business, PRIST Deemed to be University, Thanjavur, India \\ *Corresponding author: pkpristuni@gmail.com
}

\begin{abstract}
The aim of this study was to assess the employee's burnout and its impact during COVID 19 pandemic. the study which is about burnout and its impact in employees was conducted in a reputed multi-speciality hospital in Kerala during covid-19. the study is done with all possibilities to find out the burnout syndrome among the healthcare professionals, as they are the most vulnerable group in this pandemic. the stress of the employees was about to protect themselves, their family and giving compassionate care to the affected people. as the study is not meant to find out the medical aspect of burnout, it has not taken into consideration the medical aspect and hormonal impacts. as employees believe, the healthcare workers need to take extra precaution during this time, which made them more stressful.
\end{abstract}

Keywords: Consultation, COVID-19, Hospital, Kerala, Pandemic, Telemedicine.

\section{Introduction}

Burnout syndrome is an occupational phenomenon, which is due to excessive stress in the profession or place we are in. It can be briefed as the next level of stress. Stress can destruct anyone physically, so the recovery from stress is easier when compared to burnout, as burnout damages the emotional wellbeing of a person. Burnout gradually affects the health by affecting his physical, mental and social wellness. It deflates the mental stamina of a person and leads to physical fatigue and self-isolation. On its $11^{\text {th }}$ revision, International Classification of Diseases World Health Organisation specified burnout as an occupational phenomenon in 2019 making it important for organisations and its managements. WHO has not classified or included it as a medical condition.

Burnout is treated as an occupational syndrome. When an employee faces a stressful situation for a prolonged period, he may feel fatigued, his emotions may get exhausted and his concentration may deplete. It leads to low productivity and finally ends up with less accomplishment. This less accomplishment will trigger his emotional distress, as he is no longer self-motivated. The emotional distress will lead to physical reflections like aches, short temper, irritated etc. If we could not ventilate his feelings, it may end up in major psychological impacts. If we consider the healthcare professionals, they deal with number of cases, if they are not motivated, depersonalisation may develop in them. This depersonalisation and emotional distress are related to each other. Both these will lead to the less accomplishment and will elicit negative thought generating process. A health care worker may feel that he is not fit for the job. He may not be able to identify the need and give care. As in the field of healthcare, the care is provided by a team. So there are more chances of a thought of less accomplishment, if we are not in a good team. If the care giver is not emotionally stable, he cannot deliver the best possible service. Especially in the emergency and critical care areas, where caregiver has to put all his attention under stressful condition, the emotional stability plays an inevitable role in providing quality care.

The impact of burnout in healthcare professionals will directly reflects to patients, the employees are the face of the organization, they are the contact point and care providers. A disturbed care provider may not have the tolerance to listen the patient and deliver quality of time and care. The result of a disturbed employee can be seen in an unsatisfied patient. Unsatisfied patients can affect the morale of the employee. Then the employee may not feel comfortable at work and it may lead to absenteeism. The next level of continues absenteeism is employee turnover. The impact of this stage is developing escapism in employees. He may land up in drugs or alcoholism. Personal disorientation may lead to insomnia and lead to marital issues. To assess and study the level of burnout, there are many tools developed by renowned researchers. One of its kind is Maslach's Burnout Inventory (MBI).

\section{Methods and Materials}

Doctors, nurses and other staff working in M.A.J. Hospital are considered for the study. Random sampling is used and data collected through personal interviews. 200 samples were taken during April to June 2020.The leading books and journal relating to management and medical aspects of burnout are considered. 


\section{History}

In the early 1970's, Burnout was evaluated by Freudenberger followed by Maslach and co-workers. During the initial phases, it was considered that employees with people oriented profession are the only affected ones. Later studies proved that high performing professionals are the victims. After this, more researchers came into break the ice berg, it is found that even children are prone to burnout. As the expectations and disappointments are correlated, people live with high expectations and if the expected outcome is not delivered, it will turn to disappointment and depressions. So it can be concluded that, prolonged stress can result burnout in anyone at anywhere.

\section{Stress vs. Burnout}

Melinda Smith, in her journal "Burnout prevention and treatment" specifies the causes of burnout which covers all the possible causes of burnout syndrome including job, lifestyle and personality related reasons. The journal focuses on finding out and prevents burnout. It is also advised to the vulnerable group to keep an eye on burnout symptoms through three R's, that is Recognise, Reverse and Resilience. The journal concludes with the strategies to prevent tackle burnout.

There are few differences when we consider stress and burnout. It is relevant to know the differences as stress and burnout syndrome are related. They are;

\begin{tabular}{|c|c|c|}
\hline A. Description & B. Stress & C. Burnout \\
\hline D. Character & $E$. Over engagement & $F$. Disengagement \\
\hline G. Emotion & H. Over Reactive & I. $\quad$ Bunted \\
\hline $\begin{array}{ll}J . & \text { Nature }\end{array}$ & $\begin{array}{ll}K . & \text { Rush and } \\
& \text { Hyperactivity } \\
\end{array}$ & $\begin{array}{ll}L . & \text { Vulnerability and } \\
\text { despondency }\end{array}$ \\
\hline$M$. Indicator & $N$. Laziness & $O$. Discouraged \\
\hline$P$. Reflection & 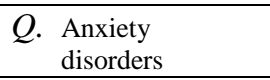 & $R$. Depression \\
\hline S. Output & $\begin{array}{ll}\text { T. } & \begin{array}{l}\text { Physical } \\
\text { impairment }\end{array} \\
\end{array}$ & $U$. Emotional destruction \\
\hline V. After effect & $\begin{array}{l}W . \text { May kill us } \\
\text { prematurely }\end{array}$ & $\begin{array}{l}X . \\
\text { May make life seem not } \\
\text { worth living }\end{array}$ \\
\hline
\end{tabular}

Burnout often relates to our career. Those who treat themselves as overworked and undervalued are prone to burnout syndrome. It may range from highly performed professional to a hardworking office boy. The burnout need not alone be an outcome of stressful life and over responsibilities. There are other factors like our life style and personality traits. How we look at the world and what we do in our downtime also plays an important role for overwhelming stress at work or home. The causes for burnout can be explained broadly as;

\section{A. Job related factors}

- Feeling of having decreased control over work.

- Less acknowledgment or incentive for high performance.

- Lack of job specifications and high expectations.

- Repetitive jobs.
- Being in unorganised team or environment

B. Lifestyle factors

- No one to express the true feelings.

- Maintaining distance from friends and family and involving completely in job.

- Shouldering responsibilities and engaging without delegating it.

- Sleeplessness.

C. Personality factors

- Perfectionist tendencies.

- Pessimistic view.

- High achiever.

- Doing everything by themselves.

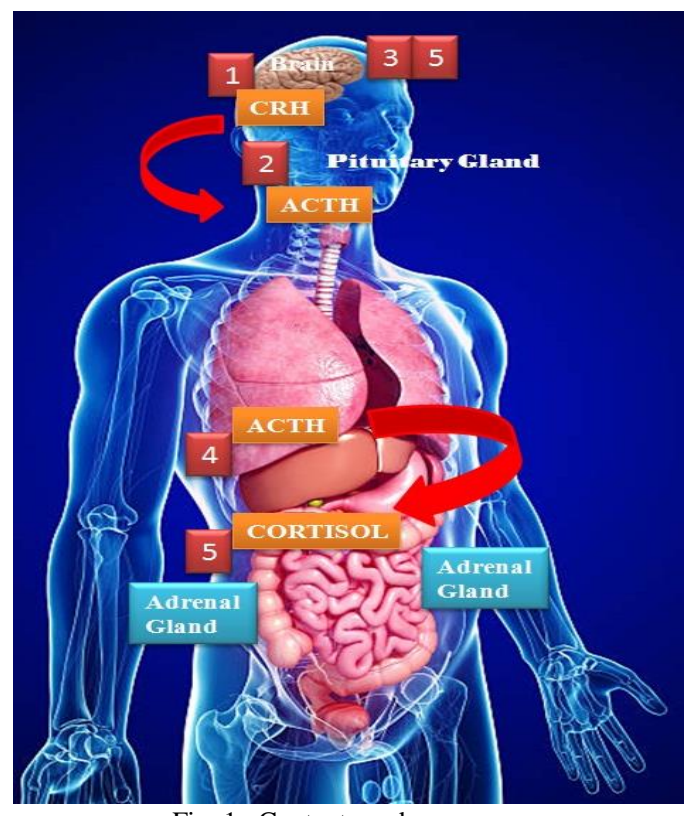

Fig. 1. Contents under pressure

D. Physiology of Burnout

1. It is found that, if we are facing a pressurized situation, our brain stimulates and produces signals by secreting a Corticotropin Releasing Hormone (CRH).

2. $\mathrm{CRH}$ is the brains communication to pituitary gland to generate Adreno Corticotropin Hormone or ACTH.

3. CRH is supposed to affect the behaviour by signalling brain regions.

4. It is also found that ACTH pass through the bloodstream and causes the adrenal gland to produce Cortisol. It is known for the stress.

5. Cortisol makes the glucose level high and prevents the immune system from over reacting to injuries. It ensures that the brain doesn't secrete too much of CRH. This keeps stress reaction from escalating out of control. 


\section{Results and Discussion}

In the present study it is seen that the employees are working happily. But they are prone to burnout as the situation demands them to work longer duration, threat of COVID-19 pandemic, continued use of PPE and uncertainty about the present socio economic conditions. It is advised to conduct more training programs and brain storming sessions. The need to develop an assurance of a sense of belonging is also important.

Table 1

Result of physical and emotional expressions

\begin{tabular}{|l|c|}
\hline \multicolumn{1}{|c|}{ Criteria } & Mean \\
\hline Feeling of tiredness & 2.12 \\
\hline Feeling fatigue & 1.90 \\
\hline Experiencing unexplained sadness & 2.24 \\
\hline Physical Complaints/sickness & 3.08 \\
\hline Feeling of less physical and emotional energy & 1.62 \\
\hline
\end{tabular}

The standard mean to be away from burnout stage is 2.1. In the present survey, people are feeling more physically ill. It is actually a symptom of burnout. But by considering the present situation of pandemic, we should keep in mind that people generally feel that they are affected and sick. Probably this pandemic situation triggers these criteria high. Feeling of tiredness and fatigue almost give the border line answers. But everyone is steady with their physical and emotional balances.

Table 2

Emotional expressions

\begin{tabular}{|l|l|}
\hline \multicolumn{1}{|c|}{ Criteria } & Mean \\
\hline Hardworking with less achievements & 2.04 \\
\hline Increasingly cynical & 1.80 \\
\hline More Irritable & 1.84 \\
\hline Short Tempered & 2.82 \\
\hline Feelings of loneliness & 2.22 \\
\hline
\end{tabular}

This table says employees are often short tempered. This is a symptom of stress and burnout. Usually when we feel nothing is happening as we plan, there short temper starts triggering. It also says employees have a border line feeling of loneliness. Probably these are the output of the pandemic, as in this situation, work rearrangements and a lot of restrictions were introduced. Also employees are worried about their health, despite the hospital providing all safety measures.
Table 3

Satisfaction level being an employee

\begin{tabular}{|l|l|}
\hline \multicolumn{1}{|c|}{ Criteria } & Mean \\
\hline Negative thoughts about job & 2.22 \\
\hline Less Job satisfaction & 1.84 \\
\hline Feeling of working for wrong organisation or profession & 1.82 \\
\hline Thinking of leaving the job & 1.62 \\
\hline
\end{tabular}

Except negative thoughts, employees are in a comfortable zone. Like the other table shows, this may be because of the pandemic. As a lot of work arrangements and restrictions have been imposed, so the revenue, job security etc. are in concern, even though management has assured job security. The very less thought of leaving job in the current situation shows the sense of belonging in the employees.

\section{Conclusion}

The Employees need to be more motivated and trained to face the current pandemic situation. Proper communication should be given about the day to day happenings and developments, as they are worried about their health too. They need to be trained more to be motivated and more productive.

\section{References}

[1] Harsh Bargava and Annie Acharya, "Burnout Prevention and Employee Retention: An Analysis", The ICFAI Journal of Organizational Behaviour, pp. 28-37, April 2006.

[2] B. D. Basava "Banish Burn-Out", The Week Xtra - September 3, 2006, pp. 14-16.

[3] Melinda Smith, Jeanne Segal, and Lawrence Robinson, "Burnout prevention and treatment",

https://www.helpguide.org/articles/stress/burnout-prevention-andrecovery.htm, October 2019.

[4] Hearher K. Spense Laschinger, Michael Leiter and Debra Gilin, "Workplace empowerment, incivility and burnout: impact on staff nurse recruitment and retention outcomes," Journal of nursing management, vol. 17, pp. 302-311, 2009.

[5] Deepak Langade, Pranav D. Modi, Yazad F. Sidhwa, Namitha A. Hishikar, Amit S. Gharpure, Kalpana Wankhade, Jayashree Langade, Kedar Joshi, "Burnout sundrome among medical practitioners across India: a questionnaire based survey," cureus, 8(9), 2016.

[6] Pérez-Fuentes, M., Molero Jurado, M., Martos Martínez, Á., \& Gázquez Linares, J. J. (2018). New Burnout Evaluation Model Based on the Brief Burnout Questionnaire: Psychometric Properties for Nursing. International journal of environmental research and public health, 15(12).

[7] Ingibjörg H. Jonsdottir and Anna Sjörs Dahlman, "Endocrine and immunological aspects of burnout: a narrative review", European Journal of Endocrinology, 180, 147-158, 2019.

[8] Tamar Kakiashvili, Jerzy Leszek, and Krzysztof Rutkowski, "The Medical Perspective On Burnout", International Journal of Occupational Medicine and Environmental Health, 2013; 26(3):401-412.

[9] Burn-out an occupational phenomenon, 11th revision of International Classification of Diseases, World Health Organisation, https://www.who.int/mental_health/evidence/burn-out/en/ 